\title{
Providing Data Insights to Suppliers for Product Development: Incentive Analysis of an E-Tailer
}

\author{
Bingqin Dai, ${ }^{1}$ Nian Liu, ${ }^{2}$ and Zhaoquan Jian $\mathbb{D}^{1}$ \\ ${ }^{1}$ School of Business Administration, South China University of Technology, Guangzhou 510640, China \\ ${ }^{2}$ School of Management, Wuhan Polytechnic University, Wuhan 430023, China \\ Correspondence should be addressed to Zhaoquan Jian; jianzq@163.com
}

Received 27 April 2021; Revised 22 August 2021; Accepted 16 September 2021; Published 14 October 2021

Academic Editor: Lianbo Ma

Copyright (c) 2021 Bingqin Dai et al. This is an open access article distributed under the Creative Commons Attribution License, which permits unrestricted use, distribution, and reproduction in any medium, provided the original work is properly cited.

Many suppliers invest in product development for market expansion via product development efforts. However, not all suppliers have accumulated market information, which is a critical factor for efficient product development that helps suppliers know consumer preferences better. Being aware of this, some e-tailers (e.g., JD.com) provide market information and data insights for their suppliers, which improves the latter's product development efficiency. Supported by the market information, the market potential of suppliers' products can be enlarged and their pricing power may be strengthened, which affects e-tailers from both positive and negative aspects. Based on these observations, we investigate an e-tailer's incentive to share market information to its suppliers by formulating the tradeoffs among market expansion, product development efficiency, and suppliers' pricing decisions. We find that the e-tailer prefers sharing market information with its suppliers when the latter's product development efficiency is high, or the product development efficiency is high but the efficiency improvement rate is high.

\section{Introduction}

Modern data collection and analysis technologies (e.g., big data analytics) have brought an explosion in both the scope and volume of market data, which includes valuable market information for firms that produce goods and sell to the market. Specifically, big data analytics is commonly known as the technology which employs massive data and scientific analysis methods to help make optimal (or near-optimal) operations (e.g., product development) for firms based on accurate information. For the role of big data analytics on firms' product development, a report from McKinsey \& Company confirms the truth that the market information mined by big data analytics is a strong driving force to product development. It points out that market information helps to improve product development efficiency, shorten product development cycle time, and reduce investment costs for suppliers [1]. Some empirical studies also justify that the accurate market information derived from big data analytics, including consumer's preferences over product properties, makes suppliers know their consumer taste well and ensures the time and cost invested in product development do not go to waste, resulting in fewer obstacles to product development or less demand uncertainties $[2,3]$. Being aware of these benefits, a survey reports that $84 \%$ of industry-leading firms in the United States and worldwide have started big data analytics initiatives to decrease expense on the process of product innovation and eliminate demand uncertainty as well [4]. Based on the above observations, it is no doubt that firms can effectively facilitate product development efficiency by using advanced big data analytics to conduct data processing and thus produce effective market information to know consumer preference well, eliminate demand uncertainty better, and so on.

However, in practice, upstream firms (i.e., suppliers) rarely know market information because of the remoteness of the end market [5], which means that they lack the accumulated market information to apply to product development (i.e., with a poor product development efficiency) and confronts significant demand uncertainty as well. In contrast, their downstream partners (i.e., retailers) usually have better access to market information because they are 
close to the end market and have advanced big data analysis technologies [6, 7]. An important problem naturally arises: Is it possible for a retailer to provide market data/information insights to its suppliers for their product development? We observe that some retailers have provided their suppliers with market information for free, which is insightful for their suppliers' product development. For example, JD's data insights have helped its suppliers boost sales. Leveraging JD's data insights, the sales of Huggies's new diapers in China have increased by more than $62 \%$ [8]. Similarly, Amazon has launched an AWS Data Exchange Project, which offers the participating suppliers access to obtain Amazon's private data sets [9].

Having said that, whether retailers have enough incentive to provide suppliers with market information is not clear. There is a concern that if the retailer provides market information, suppliers will strategically utilize the market information to adjust their pricing decisions. Consequently, this may reduce retailers' profit margins and undermine their profitability [10]. Therefore, the extant literature (e.g., $[6,7])$ suggests that retailers should always be reluctant to provide their market data with suppliers to maintain an information advantage in the supply chain. However, providing market information has many benefits for retailers. For example, market information improves suppliers' product development efficiency and reduces demand uncertainty; as a result, cost-efficient product development may drive suppliers to improve their innovation effort level so as to enlarge total market potential. Thus, such benefit bringing from the enlarged market potential stimulates the demand and then makes retailers benefit from sales boost. Being aware of these, our research questions are as follows: (1) Do retailers have incentives to provide market information with suppliers? What is the condition? (2) How are retailers' incentives affected by some important factors (e.g., product competition, market uncertainty, and else)?

To answer the aforementioned research questions, we build a stylized model comprising two suppliers and a retailer; both suppliers produce substitutable goods and sell to market via the retailer. Therefore, the retailer engages in selfcompetition in the market. As elaborated above, we assume the retailer possesses market data/information and decides whether to keep it private or share it with its suppliers who are uninformed. Such market data helps suppliers improve product development efficiency and eliminate demand uncertainty. We consider the case where the retailer (does not provide) provides market information with suppliers, which is defined as (Scenario N) Scenario S. The main results are summarized as follows.

Regarding the e-tailer's preferences over market information sharing, we show that, given a high product development efficiency, or a low production development efficiency with a high efficiency improvement rate, the e-tailer prefers sharing market information with its two suppliers. The reasons are as follows. We note that the e-tailer's profits can be divided into two parts, that is, (1) the riskless profit and (2) the risk profit because of market information sharing. We find that the e-tailer always obtains a higher riskless profit in Scenario $S$ because it can increase retail margin in Scenario S significantly, which covers its market demand size loss in Scenario S. However, whether the e-tailer can obtain higher risk profit in Scenario S depends on the two suppliers' production development efficiency and the efficiency improvement rate because of market information sharing. Given a high product development efficiency, the e-tailer enjoys the higher riskless and risk profits, so it prefers sharing information. Given a low product development efficiency with a high efficiency improvement rate, the e-tailer suffers risk profit loss but its riskless profit advantage in Scenario $S$ is more significant, which dominates the risk profit loss. Hence, market information sharing is preferred for the e-tailer in this case. We then study whether the two suppliers can be better off because of market information sharing. We find that the two suppliers obtain higher profits in Scenario $S$ because their wholesale prices increment is so significant that it offsets the loss of market sizes.

Compared to the existing literature, we have a common interest in the information sharing decision in the supply chain, which is meaningful in the era of e-commerce. Differently, we note that the e-tailers' information may be insightful for suppliers' product development, which is critical but new in the literature. We note that the previous studies such as those of Zhu et al. [11] and Huang et al. [5] focus on the problem of product development and information sharing in the supply chain, respectively, but they do not consider the two critical factors in a model framework. This paper, therefore, complements the existing literature by identifying the roles of e-tailer's information sharing in the suppliers' product development, and the e-tailer's strategic information sharing decision is also investigated carefully. On the other hand, as the e-tailers' data advantage prevails in the age of e-commerce, this paper provides an analytical framework to examine the interactions between the e-commerce platforms and their suppliers. This may be meaningful.

The rest of this paper is organized as follows. Section 2 reviews the related literature. We introduce the model settings and describe the assumptions in Section 3. Section 4 presents the elated equilibrium outcomes. We provide corresponding analysis and numerical analysis in Section 5 and Section 6, respectively. Section 7 concludes this paper and discusses the future research directions. All the proofs are summarized in the Appendix.

\section{Literature Review}

This study is related to three streams of literature: (1) product development and $\mathrm{R} \& \mathrm{D}$ investment in the operations management field, (2) the incentives of information sharing in supply chains, and (3) competition and cooperation in the supply chain.

Our work is related to the literature on product innovation and $R \& D$ investment in the operations management field. Krishnan and Ulrich [12] reviewed extensively the early literature on product development and innovation, and they showed that most papers in this literature study a single firm's product innovation and development. Zhu et al. [11] 
showed that a buyer's effort in pushing investment to improve supplier's product quality can significantly reduce the buyer's goodwill costs and market demand loss. However, the type of innovation considered in this paper differs from ours in that the brand owners' production innovation enlarges total market potential. Bhaskaran and Krishnan [13] examined which investment cost-sharing and revenuesharing mechanisms are optimal to make participated firms benefit from innovation collaboration. Wang et al. [14] employed a model consisting of a supplier and a manufacturer to investigate the interaction between supply chain contracts and endogenous upstream innovation. Yoon [15] studied an encroached manufacturer's cost-reducing investment and its spillover to the reseller, which mitigates the double marginalization effect. Hu et al. [16] studied ex-ante uncertainty values of innovation and an innovator's sourcing strategies from a competitive contract manufacturer or from a noncompetitive contract manufacturer in a supply chain, where the innovation design may spill over to a competitive contract manufacturer. Differently, we study an e-tailer's incentives of sharing private market information with its supplier for helping them develop products, and two suppliers' product development efforts enlarge market potential because of knowing consumers' preferences well and their product satisfies more consumers. This appears new in theoretical studies.

Our study is broadly related to the stream of information sharing literature, which has become a hot topic in recent years. According to the flow direction of information in the supply chain, the literature on information sharing can be classified into horizontal information sharing and vertical information sharing. Regarding horizontal information sharing, earlier literature mostly investigates whether each duopolist will make his demand signal known to the rival at the same level (e.g., [17-20]). More recently, there has been quite a large literature in OM studies that try to generalize horizontal information sharing to vertical information sharing in supply chains. Some typical studies consider interactions between vertical members in a two-level supply chain that includes a manufacturer and many downstream retailers that have private demand information (e.g., $[7,21,22])$. In different supply chain structures, Ha et al. [6] adopted a chain-to-chain competition model where they investigated retailers' vertical information sharing decisions under the impact of manufacturers' production diseconomies. Similarly, Bian et al. [23] examined supply chain parties' incentives of bilateral information sharing under chain-to-chain competition, where both the manufacturer and the retailer have partial demand information. Choi et al. [24] highlighted that horizontal information sharing among competitors improves supply chain efficiency and achieves supply chain coordination when there are multiple uncertainties. Considering ex post information sharing, Lei et al. [25] showed that the informed retailer has no incentive to share such private information to both upstream suppliers when there is high demand information because high demand information prompts suppliers to charge high wholesale prices. Compared to their study, we have a common interest in studying supply chain members' information sharing decisions. Differently, we discuss an e-tailer's incentives of market information sharing with its suppliers who invest in product development but may be inefficient. We consider the impact of the fact that market information improves suppliers' production development efficiency and eliminates demand uncertainty via e-tailer's data insights.

There is arising literature on the impact of competition and cooperation on supply chain performance. For example, typical studies such as that by McGuire and Staelin [26] suggest that tense competition may induce supply chain decentralization to become the best option for supply chain members in a chain-to-chain model. Ganeshan et al. [27] studied a supplier competition model comprising a reliable supplier and an unreliable supplier. They suggested that supplier competition helps lower wholesale prices, which benefits the downstream members. In recent years, supplier/ manufacturer encroachment arises as a hot topic concerning strategic decisions such as channel structure, upstream entry and downstream cooperation, and the combination of information flow and/or cash flow. For example, Arya et al. [28] found that competitive supplier's encroachment might reduce wholesale price and soften competition, resulting in the opportunity for a retailer to gain more profit. Hong and Guo [29] studied how contract types between manufacturer and retailer impact system performance and environmental sustainability in a green product supply chain and showed that a cost-sharing contract can coordinate the supply chain when the manufacturer has an incentive of encroaching. Guan et al. [30] showed that supplier's encroachment may come along with its voluntary information disclosure, which eventually results in improved information transparency and customers' quality perceptions. Different from the forgoing works, we study supply chain parties' incentives over demand information sharing and consider that a supply chain contains two suppliers and an e-tailer that engages in self-competition in the market and vertical competition in the supply chain.

\section{Model Framework}

We consider a two-tier supply chain consisting of two small suppliers (suppliers 1 and 2) and a powerful downstream retailer (e.g., JD.com and Amazon) that is reselling the two competing suppliers' partially substituted products in the downstream market. The two small suppliers develop their new products with development efforts (denoted as $d_{S 1}$ and $d_{S 2}$ ) and sell them by a wholesale price contract to the retailer, namely, $w_{S 1}$ and $w_{S 2}$. The retailers such as JD.com and Amazon will confront demand uncertainty when they sell the two products to the market, so many of them have applied advanced information technologies (e.g., big data analytics) to obtain massive market information, thereby mitigating the risk of demand uncertainty.

Given the supply chain structure, the retailer is optional to choose from two information sharing scenarios: (1) no information sharing (Scenario $\mathrm{N}$ ), where the retailer does not share its massive market information with the two competing suppliers, and (2) information sharing (Scenario 
S), where the retailer shares its massive market information with the two competing suppliers ([31] Figure 1 demonstrates the supply chain structures of Scenario N and Scenario $S$, where the retailer, supplier 1, and supplier 2 are denoted by $R, S 1$, and $S 2$, respectively.

As observed in practice, the retailer utilizes big data analytics to provide more accurate market information (e.g., sales quantity) for its upstream suppliers, which can help the suppliers achieve two objectives. The first is demand uncertainty elimination, and the second is the improvement of product development efficiency [1]. Therefore, we have the following descriptions:

(1) In Scenario $N$. The two suppliers do not have accurate market information; hence, both of them have to decide their wholesale prices (i.e., $E\left[w_{S 1}^{N}\right]$ and $\left.E\left[w_{S 2}^{N}\right]\right)$ and product development effort levels (i.e., $E\left[d_{S 1}^{N}\right]$ and $\left.E\left[d_{S 2}^{N}\right]\right)$ based on prior expectation. On the other hand, they have to bear the low product development efficiency because of lacking accurate market information. We use $(1 / 2) \mathrm{kd}_{i}^{N^{2}}$, where $i \in\{S 1, S 2\}$, to represent the product development cost of the suppliers, which is widely used in many studies (e.g., $[13,14,32,33]) . k$ is a technological parameter related to the product development efficiency of the suppliers. Clearly, a large $k$ indicates a low product development efficiency, which means that the investment of product development is costly.

(2) In Scenario S. The two suppliers have access to the accurate market information from the retailer; thus, both of them can decide their wholesale prices (i.e., $w_{S 1}^{S}$ and $w_{S 2}^{S}$ ) and product development effort levels (i.e., $d_{S 1}^{S}$ and $d_{S 2}^{S}$ ) based on informed market information. In addition, both of them enjoy the higher product development efficiency compared with that in Scenario $\mathrm{N}$ with the help of accurate market information. We use $(1 / 2) \lambda \mathrm{kd}_{i}^{S^{2}}$, where $i \in\{S 1, S 2\}$, to represent the product development cost of the suppliers in Scenario S. Particularly, $0<\lambda<1$ demonstrates the product development efficiency improvement rate (efficiency improvement rate for short) of the suppliers in Scenario $\mathrm{S}$. Clearly, a small $\lambda$ indicates a significant improvement of product development efficiency.
We use Bertrand competition model to formulate the downstream market competition between the two suppliers' products (or the retailer's self-competition). Following $\mathrm{Li}$ and Zhang [22] and Shang et al. [34], the demand functions in Scenario N/S are presented as follows:

$$
\begin{aligned}
& q_{S 1}^{j}=1+d_{S 1}^{j}+\varepsilon-(1+\gamma) p_{S 1}^{j}+\gamma p_{S 2}^{j}, \\
& q_{S 2}^{j}=1+d_{S 2}^{j}+\varepsilon-(1+\gamma) p_{S 2}^{j}+\gamma p_{S 1}^{j},
\end{aligned}
$$

where $q_{S 1}^{j}$ and $q_{S 2}^{j}(j=N, S)$ are the realized demand for supplier $S 1$ and S2's products in Scenarios $N$ and $S$, and $p_{S 1}^{j}$ and $p_{S 2}^{j}$ are the retail prices set by retailer for the two products. $\varepsilon$ is a random variable representing demand uncertainty with $E[\varepsilon]=0$ and $\operatorname{Var}[\varepsilon]=\sigma^{2}$. The products are assumed to be imperfect substitutes and $\gamma>0$. Clearly, a larger $\gamma$ indicates a higher degree of substitution and greater intensity of retail competition. Without loss of generality, we normalize the base market potential to 1 , and the market expansions derived from product development are $d_{S 1}^{j}$ and $d_{S 2}^{j}$ for supplier $S 1$ and $S 2$ 's products, respectively.

The e-tailers (e.g., JD.com) have to pay the wholesale prices to their suppliers when they resell their products, so they have to decide retail prices based on the suppliers' wholesale prices. That is to say, the price markups are the e-tailers' retail margins; and the retail margins will directly affect e-tailers' profits, so we have to highlight the importance of retail margins. Moreover, some typical studies (e.g., $[22,35])$ have proved that it is easier to work with the retail margins, $m_{i}^{j}=p_{i}^{j}-w_{i}^{j}(i=S 1, S 2, j=N, S)$, rather than $p_{i}^{j}$ directly. Using $p_{i}^{j}=m_{i}^{j}+w_{i}^{j}$, we rewrite the demand function for supplier $i$ as follows:

$$
\begin{aligned}
& q_{S 1}^{j}=1+d_{S 1}^{j}+\varepsilon-(1+\gamma)\left(w_{S 1}^{j}+m_{S 1}^{j}\right)+\gamma\left(w_{S 2}^{j}+m_{S 2}^{j}\right), \\
& q_{S 2}^{j}=1+d_{S 2}^{j}+\varepsilon-(1+\gamma)\left(w_{S 2}^{j}+m_{S 2}^{j}\right)+\gamma\left(w_{S 1}^{j}+m_{S 1}^{j}\right) .
\end{aligned}
$$

Based on the discussions above, the objective profit functions of each decision-maker in two scenarios can be formulated as follows:

In Scenario $N$,

$$
\begin{aligned}
\underset{\left\{w_{S 1}^{N}, e_{S 1}^{N}\right\}}{\operatorname{Max}} E\left[\pi_{S 1}^{N}\right]= & E\left\{w_{S 1}^{N}\left[1+d_{S 1}^{N}+\varepsilon-(1+\gamma)\left(w_{S 1}^{N}+m_{S 1}^{N}\right)+\gamma\left(w_{S 2}^{N}+m_{S 2}^{N}\right)\right]-\frac{1}{2} k \cdot d_{S 1}^{N 2}\right\}, \\
\underset{\left\{w_{S 2}^{N}, e_{S 2}^{N}\right\}}{\operatorname{Max}} E\left[\pi_{S 2}^{N}\right]= & E\left\{w_{S 2}^{N}\left[1+d_{S 2}^{N}+\varepsilon-(1+\gamma)\left(w_{S 2}^{N}+m_{S 2}^{N}\right)+\gamma\left(w_{S 1}^{N}+m_{S 1}^{N}\right)\right]-\frac{1}{2} k \cdot d_{S 2}^{N 2}\right\}, \\
\underset{\left\{m_{S 1}^{N}, m_{S 2}^{N}\right\}}{\operatorname{Max}} \pi_{R}^{N}= & m_{S 1}^{N}\left[1+d_{S 1}^{N}+\varepsilon-(1+\gamma)\left(w_{S 1}^{N}+m_{S 1}^{N}\right)+\gamma\left(w_{S 2}^{N}+m_{S 2}^{N}\right)\right] \\
& +m_{S 2}^{N}\left[1+d_{S 2}^{N}+\varepsilon-(1+\gamma)\left(w_{S 2}^{N}+m_{S 2}^{N}\right)+\gamma\left(w_{S 1}^{N}+m_{S 1}^{N}\right)\right] .
\end{aligned}
$$



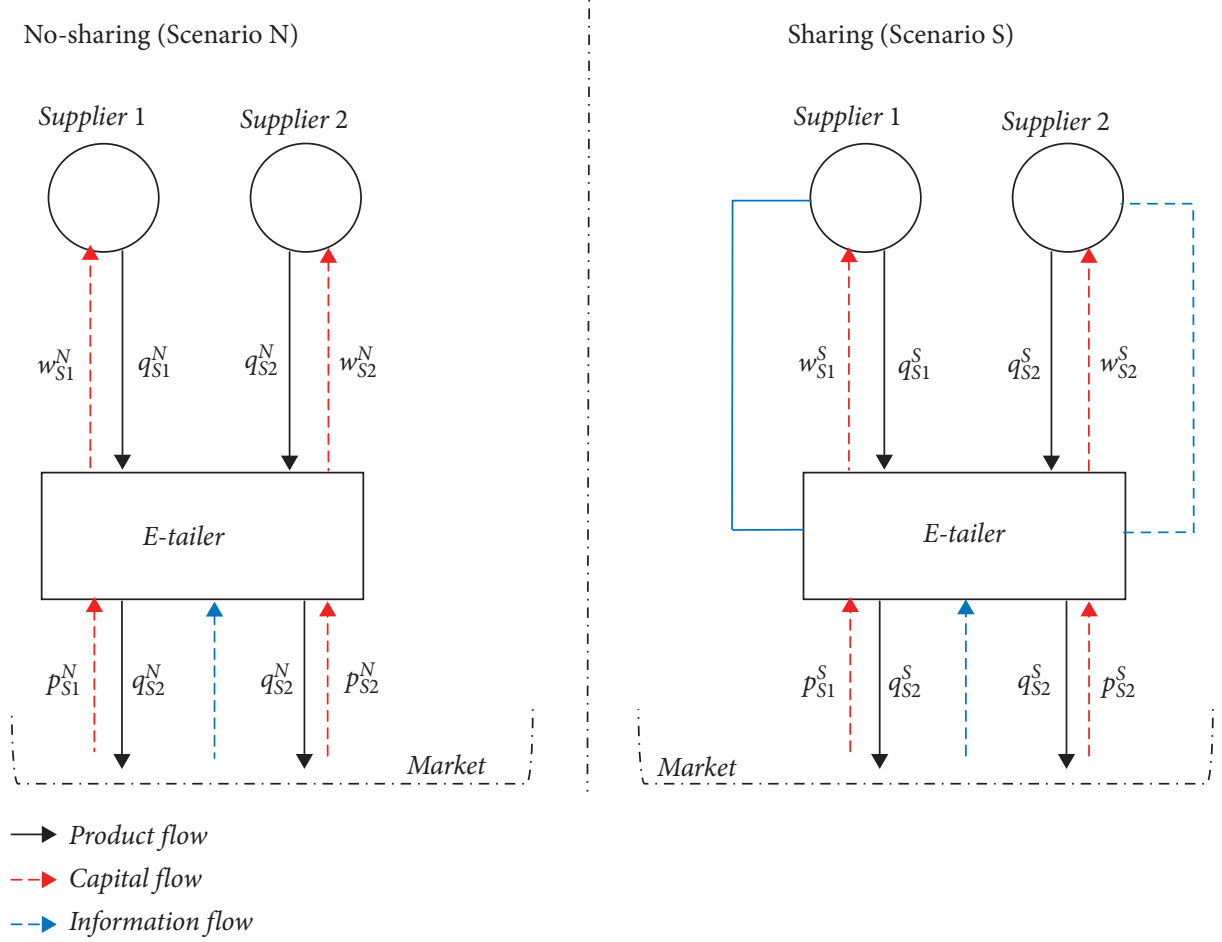

FIGURE 1: Two supply chain structures and information sharing structures.

In Scenario $S$,

$$
\begin{aligned}
& \operatorname{Max}_{\left\{w_{S 1}^{S}, e_{S 1}^{S}\right\}} \pi_{S 1}^{S}=w_{S 1}^{S}\left[1+d_{S 1}^{S}+\varepsilon-(1+\gamma)\left(w_{S 1}^{S}+m_{S 1}^{S}\right)+\gamma\left(w_{S 2}^{S}+m_{S 2}^{S}\right)\right]-\frac{1}{2} \lambda k \cdot d_{S 1}^{S^{2}}, \\
& \underset{\left\{w_{S 2}^{S}, e_{S 2}^{S}\right\}}{\operatorname{Max}} \pi_{S 2}^{S}=w_{S 2}^{S}\left[1+d_{S 2}^{S}+\varepsilon-(1+\gamma)\left(w_{S 2}^{S}+m_{S 2}^{S}\right)+\gamma\left(w_{S 1}^{S}+m_{S 1}^{S}\right)\right]-\frac{1}{2} \lambda k \cdot d_{S 2}^{S^{2}}, \\
& \underset{\left\{m_{S 1}^{S}, m_{S 2}^{S}\right\}}{\operatorname{Max}} \pi_{R}^{S}=m_{S 1}^{S}\left[1+d_{S 1}^{S}+\varepsilon-(1+\gamma)\left(w_{S 1}^{S}+m_{S 1}^{S}\right)+\gamma\left(w_{S 2}^{S}+m_{S 2}^{S}\right)\right]+m_{S 2}^{S}\left[1+d_{S 2}^{S}+\varepsilon-(1+\gamma)\left(w_{S 2}^{S}+m_{S 2}^{S}\right)+\gamma\left(w_{S 1}^{S}+m_{S 1}^{S}\right)\right] .
\end{aligned}
$$

\section{Derivation of Equilibrium Outcomes}

In this section, we solve the games by using backward induction. First, we introduce the event sequences in Scenarios $S$ and $N$. At the 1st stage, the retailer decides to share its market information with the two suppliers (Scenario $S$ or $N$ ). In Scenario $S(N)$, at the 2nd stage, the suppliers $S 1$ and $S 2$ set their product development effort levels $d_{S 1}^{S}$ and $d_{S 2}^{S}$ (expected product development effort levels $E\left[d_{S 1}^{N}\right]$ and $\left.E\left[d_{S 2}^{N}\right]\right)$ simultaneously based on accurate market information (prior expectation). At the 3rd stage, suppliers $S 1$ and $S 2$ set their wholesale prices $w_{S 1}^{S}$ and $w_{S 2}^{S}$ (expected wholesale prices $E\left[w_{S 1}^{N}\right]$ and $\left.E\left[w_{S 2}^{N}\right]\right)$ simultaneously based on accurate market information (prior expectation) in Scenario $S(N)$. At the 4 th stage, the retailer sets its retail margins $m_{S 1}^{S}$ and $m_{S 2}^{S}$ $\left(m_{S 1}^{N}\right.$ and $\left.m_{S 2}^{N}\right)$ based on accurate market information (prior expectation) in Scenario $S(N)$.

We derive the equilibrium outcomes in Scenario $S$ as an example by using backward induction. Given $\left(d_{S 1}^{S}, d_{S 2}^{S}\right)$ and $\left(w_{S 1}^{S}, w_{S 2}^{S}\right)$, the retailer decides its retail margins $\left(m_{S 1}^{S}, m_{S 2}^{S}\right)$ according to the principle of profit maximization. The optimal retail margins to maximize (3) can be given by 


$$
\begin{aligned}
& m_{S 1}^{S}\left(d_{S 1}^{S}, d_{S 2}^{S}, w_{S 1}^{S}\right)=\frac{(1+\gamma) d_{S 1}^{S}+\gamma d_{S 2}^{S}+(1+2 \gamma)\left(1+\varepsilon-w_{S 1}^{S}\right)}{2+4 \gamma}, \\
& m_{S 2}^{S}\left(d_{S 1}^{S}, d_{S 2}^{S}, w_{S 2}^{S}\right)=\frac{\gamma d_{S 1}^{S}+(1+\gamma) d_{S 2}^{S}+(1+2 \gamma)\left(1+\varepsilon-w_{S 2}^{S}\right)}{2+4 \gamma} .
\end{aligned}
$$

Substituting the optimal retail margins into supplier 1 and 2's expected profit functions (3) and (4) yields the wholesale prices of suppliers 1 and 2 :

$$
\begin{aligned}
& w_{S 1}^{S}\left(d_{S 1}^{S}, d_{S 2}^{S}\right)=\frac{(2+3) \gamma \varepsilon}{4+8 \gamma+3 \gamma^{2}}+\frac{2+3 \gamma+2(1+\gamma) d_{S 1}^{S}+\gamma d_{S 2}^{S}}{4+8 \gamma+3 \gamma^{2}}, \\
& w_{S 2}^{S}\left(d_{S 1}^{S}, d_{S 2}^{S}\right)=\frac{(2+3 \gamma) \varepsilon}{4+8 \gamma+3 \gamma^{2}}+\frac{2+3 \gamma+\gamma d_{S 1}^{S}+2(1+\gamma) d_{S 2}^{S}}{4+8 \gamma+3 \gamma^{2}}
\end{aligned}
$$

Substituting (9) and (10) into equations (7) and (8) yields $m_{S 1}^{S}\left(d_{S 1}^{S}, d_{S 2}^{S}\right)$ and $m_{S 2}^{S}\left(d_{S 1}^{S}, d_{S 2}^{S}\right)$, and substituting (9) and (10) into equations (3) and (4) yields the optimal effort levels of suppliers 1 and 2 :

$$
\begin{aligned}
& d_{S 1}^{S}=\frac{2(1+\gamma)^{2}(1+\varepsilon)}{-2+8 k \lambda+3 k \gamma^{3} \lambda+4 \gamma(-1+5 k \lambda)+2 \gamma^{2}(-1+7 k \lambda)} \\
& d_{S 2}^{S}=\frac{2(1+\gamma)^{2}(1+\varepsilon)}{-2+8 k \lambda+3 k \gamma^{3} \lambda+4 \gamma(-1+5 k \lambda)+2 \gamma^{2}(-1+7 k \lambda)}
\end{aligned}
$$

Substituting the optimal effort levels $\left(d_{S 1}^{S}, d_{S 2}^{S}\right)$ into equations (7) (10) and (3) (5) yields the optimal wholesale prices $\left(w_{S 1}^{S}, w_{S 2}^{S}\right)$, the optimal retail margins $\left(m_{S 1}^{S}, m_{S 2}^{S}\right)$, and the expected profits in Lemma 1.

Lemma 1. Effort levels are as follows:

$$
\begin{aligned}
& E\left[d_{S 1}^{S}\right]=\frac{2(1+\gamma)^{2}}{3 k \lambda \gamma^{3}+2(7 k \lambda-1) \gamma^{2}+4(5 k \lambda-1) \gamma+8 k \lambda-2}, \\
& E\left[d_{S 2}^{S}\right]=\frac{2(1+\gamma)^{2}}{3 k \lambda \gamma^{3}+(7 k \lambda-1) \gamma^{2}+4(5 k \lambda-1) \gamma+8 k \lambda-2 .}
\end{aligned}
$$

Prices are as follows:

$$
\begin{aligned}
& E\left[w_{S 1}^{S}\right]=\frac{k\left(4+8 \gamma+3 \gamma^{2}\right) \lambda}{3 k \lambda \gamma^{3}+2(7 k \lambda-1) \gamma^{2}+4(5 k \lambda-1) \gamma+8 k \lambda-2}, \\
& E\left[w_{S 2}^{S}\right]=\frac{k\left(4+8 \gamma+3 \gamma^{2}\right) \lambda}{3 k \lambda \gamma^{3}+2(7 k \lambda-1) \gamma^{2}+4(5 k \lambda-1) \gamma+8 k \lambda-2}, \\
& E\left[m_{S 1}^{S}\right]=\frac{k\left(4+12 \gamma+11 \gamma^{2}+3 \gamma^{3}\right) \lambda}{2\left[3 k \lambda \gamma^{3}+2(7 k \lambda-1) \gamma^{2}+4(5 k \lambda-1) \gamma+8 k \lambda-2\right]}, \\
& E\left[m_{S 2}^{S}\right]=\frac{k\left(4+12 \gamma+11 \gamma^{2}+3 \gamma^{3}\right) \lambda}{2\left[3 k \lambda \gamma^{3}+2(7 k \lambda-1) \gamma^{2}+4(5 k \lambda-1) \gamma+8 k \lambda-2\right]} .
\end{aligned}
$$


Expected profits are as follows:

$$
\begin{aligned}
& E\left[\pi_{S 1}^{S}\right]=\frac{\lambda k(1+\gamma)\left[9 k \gamma^{4} \lambda+\gamma^{3}(48 k \lambda-4)+4 \gamma^{2}(22 k \lambda-3)+4 \gamma(16 k \lambda-3)+16 k \lambda-4\right]}{2\left[3 k \lambda \gamma^{3}+2(7 k \lambda-1) \gamma^{2}+4(5 k \lambda-1) \gamma+8 k \lambda-2\right]^{2}}\left(1+\sigma^{2}\right), \\
& E\left[\pi_{S 2}^{S}\right]=\frac{\lambda k(1+\gamma)\left[9 k \gamma^{4} \lambda+\gamma^{3}(48 k \lambda-4)+4 \gamma^{2}(22 k \lambda-3)+4 \gamma(16 k \lambda-3)+16 k \lambda-4\right]}{2\left[3 k \lambda \gamma^{3}+2(7 k \lambda-1) \gamma^{2}+4(5 k \lambda-1) \gamma+8 k \lambda-2\right]^{2}}\left(1+\sigma^{2}\right), \\
& E\left[\pi_{R}^{S}\right]=\frac{k^{2}\left(4+12 \gamma+11 \gamma^{2}+3 \gamma^{3}\right)^{2} \lambda^{2}}{2\left[3 k \lambda \gamma^{3}+2(7 k \lambda-1) \gamma^{2}+4(5 k \lambda-1) \gamma+8 k \lambda-2\right]^{2}}\left(1+\sigma^{2}\right) .
\end{aligned}
$$

Analogically, the equilibrium outcomes in Scenario $\mathrm{N}$ can be derived as shown in Lemma 2 .

Lemma 2. Effort levels are as follows:

$$
\begin{aligned}
& E\left[d_{S 1}^{N}\right]=\frac{2(1+\gamma)^{2}}{k(2+\gamma)^{2}(2+3 \gamma)-2(1+\gamma)^{2}}, \\
& E\left[d_{S 2}^{N}\right]=\frac{2(1+\gamma)^{2}}{k(2+\gamma)^{2}(2+3 \gamma)-2(1+\gamma)^{2}} .
\end{aligned}
$$

Prices are as follows:

$$
\begin{aligned}
E\left[w_{S 1}^{N}\right] & =\frac{k\left(4+8 \gamma+3 \gamma^{2}\right)}{k(2+\gamma)^{2}(2+3 \gamma)-2(1+\gamma)^{2}}, \\
E\left[w_{S 2}^{N}\right] & =\frac{k\left(4+8 \gamma+3 \gamma^{2}\right)}{k(2+\gamma)^{2}(2+3 \gamma)-2(1+\gamma)^{2}}, \\
\left.E\left[m_{S 1}^{N}\right]\right] & =\frac{k\left(4+8 \gamma+3 \gamma^{2}\right)+k \gamma\left(4+8 \gamma+3 \gamma^{2}\right)}{2\left[k(2+\gamma)^{2}(2+3 \gamma)-2(1+\gamma)^{2}\right]}, \\
E\left[m_{S 2}^{N}\right] & =\frac{k\left(4+8 \gamma+3 \gamma^{2}\right)+k \gamma\left(4+8 \gamma+3 \gamma^{2}\right)}{2\left[k(2+\gamma)^{2}(2+3 \gamma)-2(1+\gamma)^{2}\right]} .
\end{aligned}
$$

Expected profits are as follows:

$$
\begin{aligned}
& E\left[\pi_{S 1}^{N}\right]=\frac{k(1+\gamma)\left[k\left(4+8 \gamma+3 \gamma^{2}\right)^{2}-4(1+\gamma)^{3}\right]}{2\left[k(2+\gamma)^{2}(2+3 \gamma)-2(1+\gamma)^{2}\right]^{2}}, \\
& E\left[\pi_{S 2}^{N}\right]=\frac{k(1+\gamma)\left[k\left(4+8 \gamma+3 \gamma^{2}\right)^{2}-4(1+\gamma)^{3}\right]}{2\left[k(2+\gamma)^{2}(2+3 \gamma)-2(1+\gamma)^{2}\right]^{2}}, \\
& E\left[\pi_{R}^{N}\right]=\frac{k^{2}\left[4+12 \gamma+11 \gamma^{2}+3 \gamma^{3}\right]^{2}}{2\left[k(2+\gamma)^{2}(2+3 \gamma)-2(1+\gamma)^{2}\right]^{2}}+\frac{\sigma^{2}}{2} .
\end{aligned}
$$

\section{Comparative Analysis}

In this section, we investigate the impact of the retailer's information sharing on the supply parties' (i.e., the retailer, supplier 1, and supplier 2) decision parameters and the retailer's preference of information sharing (Scenario S) by employing comparative analysis. We first examine how the information sharing affects the suppliers' efforts and wholesale prices and then derive the retailer's optimal decisions based on the incentive analysis. To avoid the trivial case, we constrain the feasible region of $k$ and $\lambda$ on $\Omega=$ $\left\{(k, \lambda) \mid k>k_{0}=2(1+\gamma)^{2} /\right.$

$\left.(2+\gamma)^{2}(2+3 \gamma), 2(1+\gamma)^{2} /(2+\gamma)^{2}(2+3 \gamma) k,=\lambda_{0}<\lambda<1\right\}$ to guarantee nonnegative equilibrium outputs. Otherwise, the analysis may not be interesting.

\subsection{Impact of Information Sharing on Efforts}

Lemma 3. For any feasible $k$ and $\lambda$, both supplier 1 and supplier 2 set a higher expected effort level in Scenario $S$ (i.e., $E\left[d_{S 1}^{N}\right]<E\left[d_{S 1}^{S}\right]$ and $\left.E\left[w_{S 2}^{N}\right]<E\left[w_{S 2}^{S}\right]\right)$.

Lemma 3 shows that suppliers 1 and 2 put more effort into product development when they obtain the retailer's market information. These results confirm our intuition. As mentioned before, the market information helps suppliers 1 and 2 improve their product development efficiency, which reduces the product development cost correspondingly. Hence, suppliers 1 and 2 will put more effort into product development with higher efficiency, making them benefit from the enlarged market potential. On the other hand, suppliers 1 and 2 actually engage in an "effort racing" when they invest in product development. After obtaining the market information, if supplier 1 does not improve the level of product development effort and supplier 2 improves its effort level, then the latter will gain more benefit from the enlargement of market potential, while the former will lose its competitive advantage. Therefore, the two suppliers are incentivized to put more product development efforts for market expansion to sell more products. At the same time, jointly considering the "effort racing," both suppliers 1 and 2 are willing to invest more (less) in product development when the retailer provides (does not provide) market information. 
5.2. Impact of Information Sharing on Prices. As discussed in Introduction, we are interested in whether the informed suppliers in Scenario $\mathrm{S}$ determine high wholesale prices because they will strategically utilize the market information in a pricing adjustment. We have the following proposition.

Lemma 4. For any feasible $k$ and $\lambda$, both supplier 1 and supplier 2 set higher expected wholesale prices in Scenario $S$ (i.e., $E\left[w_{S 1}^{N}\right]<E\left[w_{S 1}^{S}\right]$ and $E\left[w_{S 2}^{N}\right]<E\left[w_{S 2}^{S}\right]$ ).

Compared to Scenario $N$, suppliers 1 and 2 are always enjoying higher wholesale prices in Scenario $S$, which confirms our intuition. The possible explanations are as follows. First, recalling Lemma 1, we know that suppliers 1 and 2 will become more effective and put more effort into product development when they are informed in Scenario $S$, which effectively stimulates market demand of suppliers' products. Backed by enlarged market demand, suppliers 1 and 2 have incentives to raise their wholesale prices to increase their profit margins. Second, the previous literature reveals that suppliers may become more "powerful" when they are informed because market information gives them more precise price adjustment directions [5-7]. Suppliers will undoubtedly choose to increase their wholesale prices when the market demand is large. As a result, combining the foregoing two forces, suppliers 1 and 2 enjoy higher wholesale prices in Scenario $S$.

Lemma 5. For any feasible $k$ and $\lambda$, the retailer obtains higher retail margins from both product 1 and product 2 in Scenario $S$ (i.e., $E\left[m_{S 1}^{N}\right]<E\left[m_{S 1}^{S}\right]$ and $E\left[m_{S 2}^{N}\right]<E\left[m_{S 2}^{S}\right]$ ).

As Lemma 4 shows, suppliers 1 and 2 determine high wholesale prices in Scenario S, which push up the retailer's procurement costs directly. Therefore, regarding Lemma 5, it is intuitively seen that the retailer has to decide on higher retail margins in Scenario $S$ to guarantee its margin profit. Lemma 5 signifies that if the retailer provides market information with the two suppliers, this would increase its procurement costs and push up the retail prices consequently. Intuitively, the high retail prices will suppress the demand sizes of the two suppliers' products. Therefore, we have Lemma 6 as follows.

\subsection{Impact of Information Sharing on Demand Sizes}

Lemma 6. For any feasible $k$ and $\lambda$, the demand sizes of product 1 and product 2 under scenario $S$ are both smaller than those under scenario $N$ (i.e., $E\left[q_{S 1}^{N}\right]<E\left[q_{S 1}^{S}\right]$ and $E\left[q_{S 2}^{N}\right]<E\left[q_{S 2}^{S}\right]$ ).

Following the logic of Lemmas 4 and 5, we find the demand sizes of the two suppliers' products are all smaller in Scenario $S$ than in Scenario N. So Lemma 6 is consistent with our intuition because customers have to pay more when the retailer chooses to provide market information with its suppliers.

5.4. Analysis of the Retailer's Preferences. Next, we investigate the supply chain members' preferences towards the market information provided by comparing their profits in two scenarios. Define $k_{1}=2(1+\gamma)^{2} /(2+3 \gamma)(2+\gamma), \quad \lambda_{1}=2$ $\left((1+\gamma)^{2}\left\{(2+\gamma)\left[f_{2}(k, \gamma)+\left(\sigma f_{1}(k, \gamma)\right)^{2}\right]+(1+\gamma) f_{1}(k\right.\right.$, $\left.\gamma) \sqrt{\left(1+\sigma^{2}\right)\left[f_{2}(k, \gamma)+\left(\sigma f_{1}(k, \gamma)\right)^{2}\right]}\right\} / 4(1+\gamma)^{4}\left[(1+\gamma)^{2}+\right.$ $\left.f(k, \gamma)]+(3+2 \gamma)\left(\sigma f_{1}(k, \gamma)\right)^{2}\right)$, and $\lambda_{2}=2(1+\gamma)^{2} / k(4+$ $\left.8 \gamma+3 \gamma^{2}\right)$. Note that $f_{1}(k, \gamma)=k(2+\gamma)^{2}(2+3 \gamma)-2(1+\gamma)$ ${ }^{2}>0$, and $f_{2}(k, \gamma)=k(1+\gamma)^{2}(2+\gamma)^{2}(2+3 \gamma)^{2}>0$. We have Proposition 1 .

Proposition 1. For any feasible $\gamma>0$ and $\sigma>0$, the retailer prefers sharing the suppliers with market information (i.e., Scenario $S$ is better, $\pi_{R}^{S}>\pi_{R}^{N}$ ) if one of the conditions holds:

(a) $k_{0}<k \leq k_{1}$,

(b) $k>k_{1}$ and $\lambda_{0}<\lambda<\lambda_{1}$.

Proposition 1 demonstrates that the retailer's optimal decision is a threshold strategy, which depends on two parameters: the two suppliers' product development efficiency $k$ and efficiency improvement rate $\lambda$. That is, the retailer conditionally helps its upstream partners to develop products if $k$ is below or above a certain threshold $k_{1}$. In case (a), where the product development efficiency is high, that is, $k$ is small, providing market information is always a preferred strategy of the retailer regardless of the efficiency improvement rate $\lambda$. However, in case (b), when the product development efficiency is relatively low (i.e., $k>k_{1}$ ), the preference of the retailer over market information sharing is dependent on the efficiency improvement rate $\lambda$ : Only when the efficiency improvement is sufficiently high will the retailer determine to provide market information with its two suppliers. To explain Proposition 1, we first divide the retailer's profit into two parts: riskless profit $P_{L}(\gamma, k, \lambda)$ and risk profit $P_{R}(\gamma, k, \lambda, \sigma)$ (e.g., [36, 37]), where the first part is independent of demand uncertainty $\sigma$ and the second part associates with $\sigma$, and then analyze the retailer's strategic decision by investigating the interactions of these two parts. We have Corollary 1 as follows.

\section{Corollary 1.}

(a) For any feasible $\gamma>0$ and $\sigma>0$, $P_{L}^{S}(\gamma, k, \lambda)>P_{L}^{N}(\gamma, k, \lambda)$ holds; that is, the retailer's riskless profit is larger in Scenario $S$ than in Scenario $N$.

(b) $P_{R}^{S}(\gamma, k, \lambda, \sigma)>P_{R}^{N}(\gamma, k, \lambda, \sigma)$ holds; that is, the retailer's risk profit is larger in Scenario $S$ than in Scenario $N$ if one of the conditions holds:

(bi) $k_{0}<k \leq k_{1}$,

(bii) $k>k_{1}$ and $\lambda_{0}<\lambda<\lambda_{2}$.

From Corollary 1, we find that the e-tailer could obtain higher riskless and risk profits when it shares data with suppliers and the two suppliers have a high product development efficiency $k$ (i.e., $k<k_{1}$ ) or a low product development efficiency $k$ and a high efficiency improvement rate $\lambda$ (i.e., $k>k_{1}$ and $\lambda<\lambda_{2}$ ), which makes it become better off in Scenario $\mathrm{S}$. This interprets why the e-tailer is best to share data with effective suppliers when $k<k_{1}$ or $k>k_{1}$ and $\lambda<\lambda_{2}$ because high product development efficiency helps e-tailer enjoy 
the higher marginal profits (see Lemma 5). See an illustration in region 1 of Figure 2.

On the contrary, given a large $k$, which means the two suppliers suffer from low efficiency in product development, the efficiency improvement rate $\lambda$ plays a critical role in the e-tailer's profit structures. More specifically, we find that the e-tailer could still enjoy a higher riskless profit (i.e., $\left.P_{L}^{S}(\gamma, k, \lambda)>P_{L}^{N}(\gamma, k, \lambda)\right)$ but suffers a risk profit loss (i.e., $\left.P_{R}^{S}(\gamma, k, \lambda, \sigma)>P_{R}^{N}(\gamma, k, \lambda, \sigma)\right)$ in Scenario $S$ when the efficiency improvement rate $\lambda$ is relatively low (i.e., $\lambda>\lambda_{2}$ ); the former acts as the positive force, while the latter acts as the negative force. It is interesting to find that the e-tailer's riskless profit advantage is stronger than its risk profit disadvantage when $\lambda_{2}<\lambda<\lambda_{1}$. See an illustration in region 2 of Figure 2. Therefore, the e-tailer prefers to share with its suppliers when $\lambda_{2}<\lambda<\lambda_{1}$. Furthermore, investigating the impact of $\lambda$ on the e-tailer's differences of riskless and risk profits in Scenario $S$ and $\mathrm{N} \quad$ (i.e., $\quad P_{L}^{S}(\gamma, k, \lambda)-P_{L}^{N}(\gamma, k, \lambda) \quad$ and $\left.P_{R}^{S}(\gamma, k, \lambda, \sigma)-P_{R}^{N}(\gamma, k, \lambda, \sigma)\right)$, we find that both of them are decreasing in $\lambda$ and the e-tailer's riskless profit advantage is eroded by the low efficiency improvement rate $\lambda$ more rapidly compared with its risk profit disadvantage. That means the e-tailer's riskless profit advantage will be weakened significantly and its risk profit disadvantage will be also expanded as $\lambda$ increases. As a result, the e-tailer cannot benefit from the data sharing when the efficiency improvement rate $\lambda$ is very low (i.e., $\lambda>\lambda_{1}$ ). Clearly, the e-tailer will not choose to share data with its suppliers. See an illustration in region 3 of Figure 2.

Proposition 2. For any feasible $\gamma>0$ and $\sigma>0$, suppliers 1 and 2 always benefit from the information sharing; that is, $\pi_{S 1}^{S}>\pi_{S 1}^{N}$ and $\pi_{S 2}^{S}>\pi_{S 2}^{N}$ hold.

Proposition 2 demonstrates that suppliers can be better off when their channel partner (i.e., the e-tailer) shares market information, which is consistent with our intuition. The underlying reasons are as follows. Backed by the more efficient product development, the two suppliers' products could be more popular, which makes them have a strong incentive to raise their wholesale prices to increase their profit margins (see Lemma 2). However, the increased wholesale prices push up the e-tailer's procurement costs, forcing the e-tailer to set higher retail prices to ensure its retail profit margins (see Lemma 3). As a result, the high retail prices restrain the demand for products (see Lemma 4). Hence, the e-tailer's profit is affected by its profit margins and demand sizes. Comparing these twofold, we find that the loss of demand size is dominated by the benefit of profit margins increment in Scenario S. Hence, the two suppliers can benefit from the e-tailer's information sharing.

\section{Numerical Analysis}

In this section, we conduct numerical analysis to investigate the impact of market uncertainty (i.e., $\sigma$ ) and product substitutability (i.e., $\gamma$ ) on the e-tailer's preferences regions. Note that all the numerical analyses are based on the main model proposed in Section 4 and the e-tailer's preference conditions in Proposition 1.

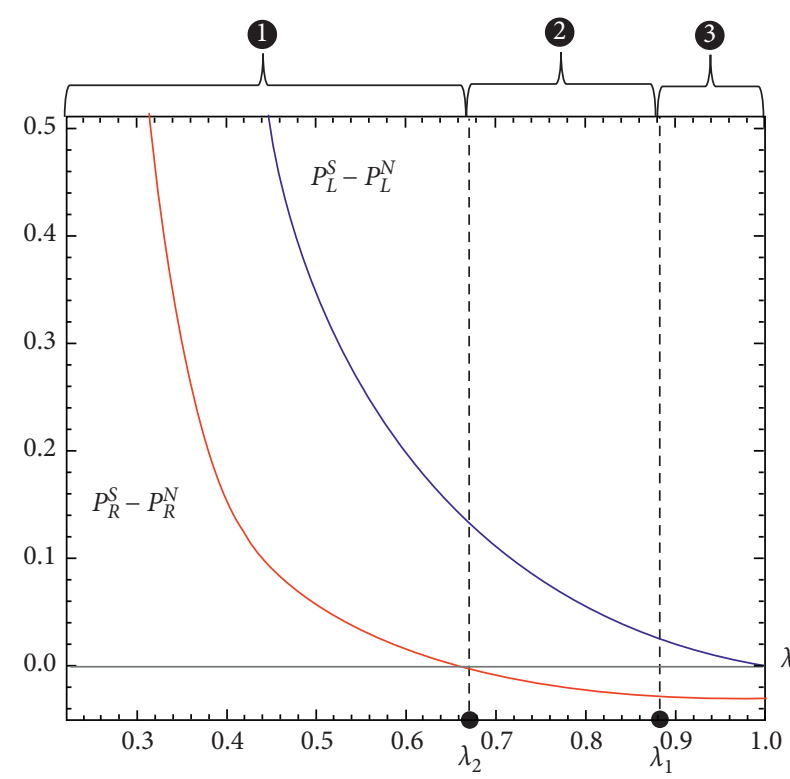

(1) The retailer's riskless and risk profits are both higher in Scenario S;

(2) The retailer's riskless profit advantage is stronger than its risk profit disadvantage in Scenario S;

(3) The retailer's riskless profit advantage is weaker than its risk profit.

Figure 2: Comparisons of the e-tailer's profit structures in scenarios $S$ and $N$.

6.1. Effect of Market Uncertainty on the E-Tailer's Preferences Areas. In this subsection, we investigate the change of e-tailer's preferences areas affected by the market uncertainty (i.e., $\sigma$ ). Figure 3 describes the main findings. The grey and green areas in Figure 3 show that the e-tailer prefers sharing market information with its suppliers when suppliers' product development efficiency is high and low, respectively, corresponding to Proposition 1's (a) and (b). Figures 3(a) and 3(b) show that the e-tailer confronts a low market uncertainty (i.e., $\sigma=0.5$ and $\sigma=1$ ), while Figures 3(c) and 3(d) show the opposite results (i.e., $\sigma=1.5$ and $\sigma=3$ ). From Figure 3, we find that the areas of e-tailer's preference over market information sharing (Scenario $S$ ) shrink as market uncertainty increases. This signifies that a higher market uncertainty weakens the e-tailer's incentive of market information sharing. This is because the higher market uncertainty not only indicates higher risk but also implies that once suppliers get market information from the e-tailer, their pricing adjustment ability will be greatly enhanced. Obviously, the e-tailer's profit margin will be squeezed as suppliers' pricing power becomes stronger; this induces the e-tailer has less incentive to share market information with its suppliers. Conversely, the area of no sharing expands as market uncertainty (i.e., $\sigma$ ) increases.

6.2. Effect of Product Substitutability on the Retailer's Preferences Regions. Similar to Subsection 6.2, we investigate the change of e-tailer's preferences areas affected by a critical 


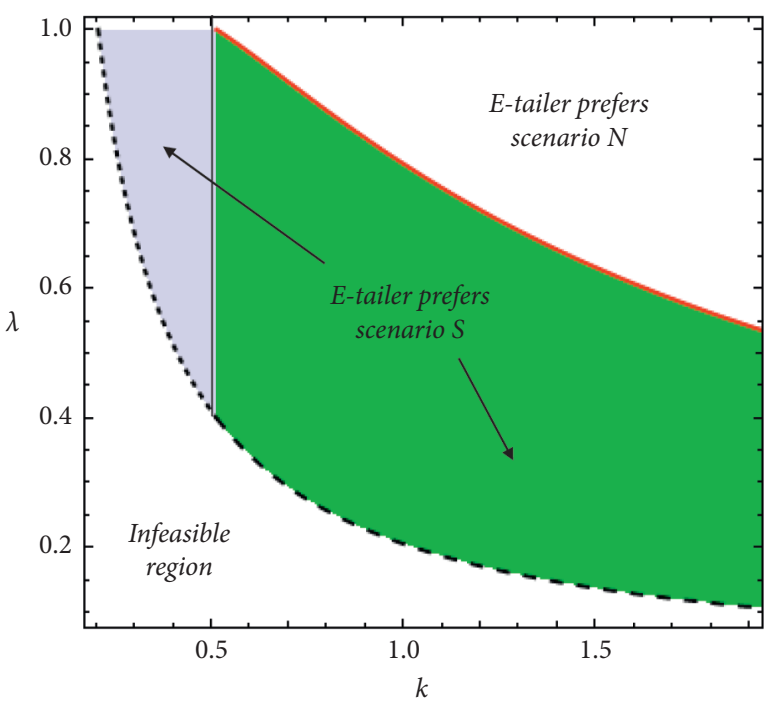

(a)

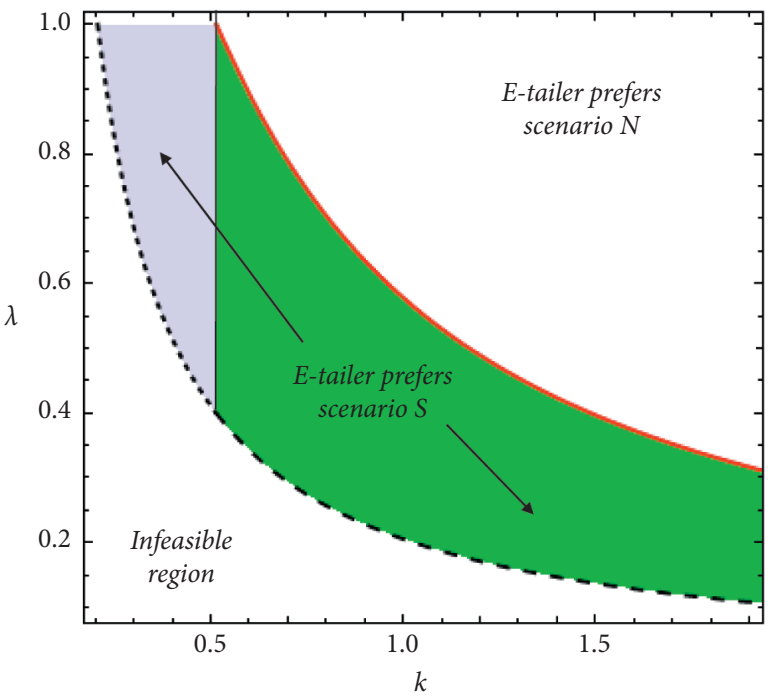

(c)

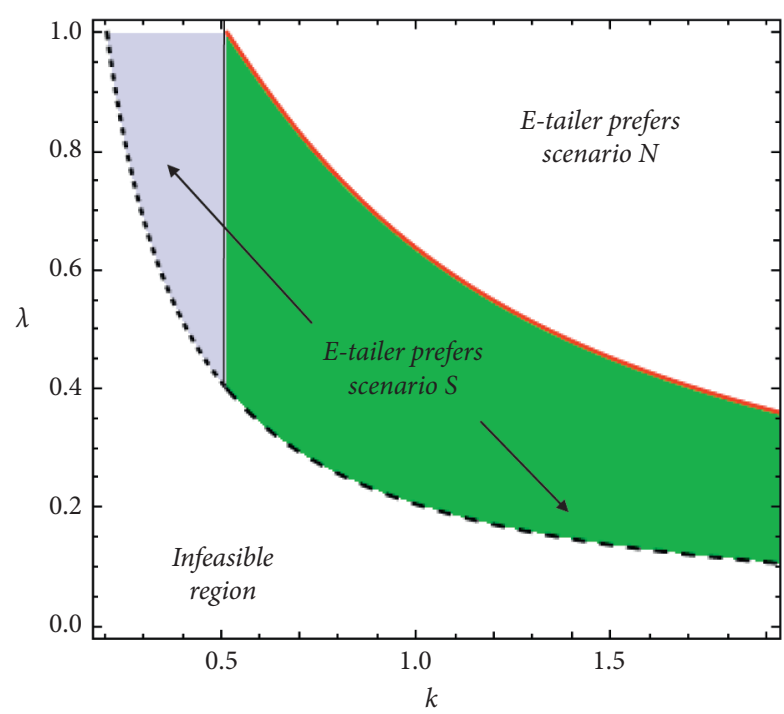

(b)

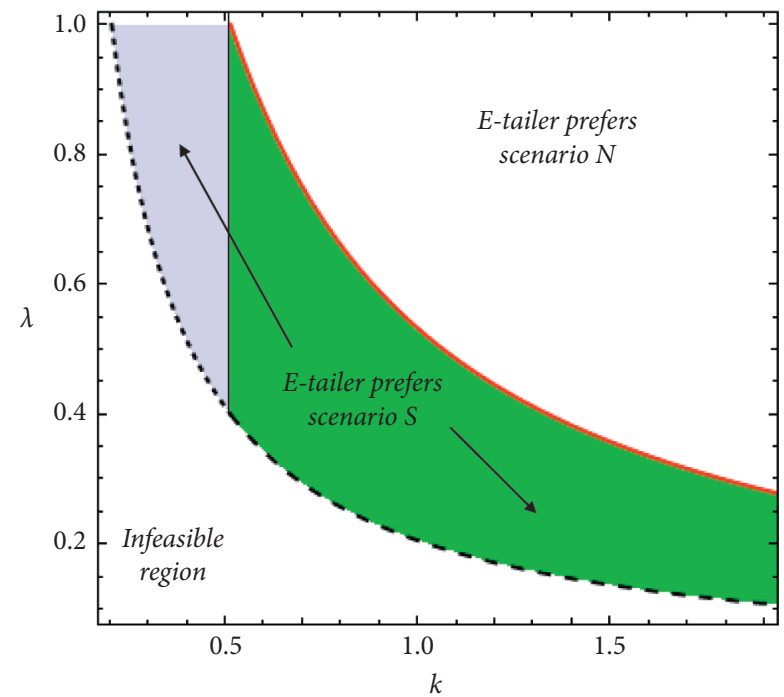

(d)

FIGURE 3: Impact of market uncertainty on the e-tailer's preferences. (a) $\gamma=0.5, \sigma=0.5$. (b) $\gamma=0.5, \sigma=1$. (c) $\gamma=0.5, \sigma=1.5$. (d) $\gamma=0.5, \sigma=3$.

factor, that is, the product substitutability $\gamma$. Similarly, the grey and green areas in Figure 4 show that the e-tailer prefers sharing market information with its suppliers when suppliers' product development efficiency is high and low, respectively, corresponding to Proposition 1's (a) and (b). Figures 4(a) and 4(b) show that the product substitutability is low (i.e., $\gamma=0.5$ and $\gamma=1.5$ ), while Figures $4(\mathrm{c})$ and $4(\mathrm{~d})$ show opposite results (i.e., $\gamma=3$ and $\gamma=6$ ). Note that the e-tailer purchases the two suppliers' substitutable products and resells them in the market, which induces the e-tailer to form a self-competition. Therefore, the product substitutability $\gamma$ also indicates the competition intensity. Intuitively, fierce competition may make the e-tailer and the two suppliers worse off because of the system efficiency loss. However, Figure 4 describes some counterintuitive findings; that is, the areas of e-tailer's preference over market information sharing (Scenario S) expand as competition becomes fierce. This signifies that the fiercer product competition encourages the e-tailer to share market information with its suppliers. This is because when the two suppliers do not have market information, the inefficient product development will not enlarge their market potential significantly, and the fierce competition will pull down the retail prices of the two products, which ultimately results in the e-tailer suffering demand loss and profit margin loss. Being aware of this, the e-tailer will be more willing to share market information with suppliers as competition becomes fierce, which helps them enlarge market potential significantly and obtain a higher retail profit margin (see Lemma 5). 


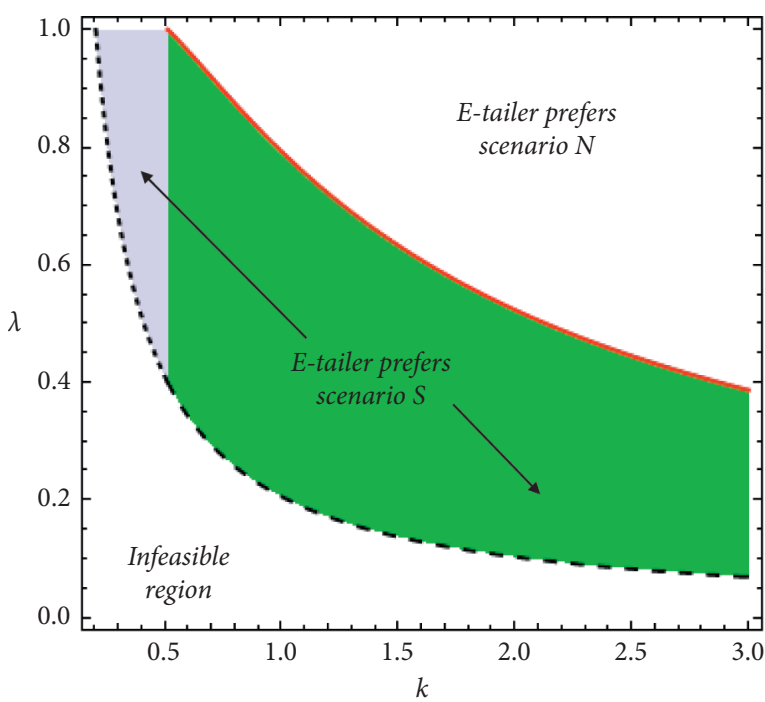

(a)

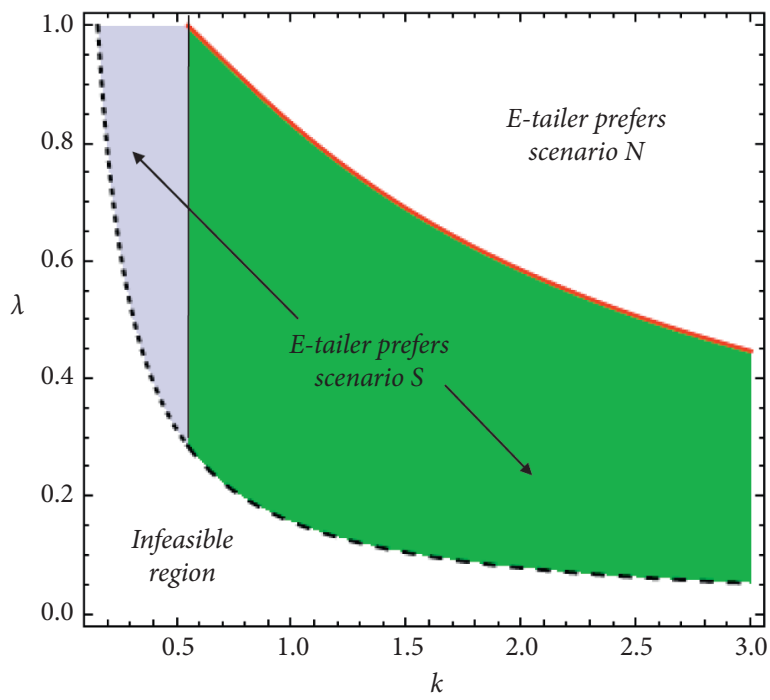

(c)

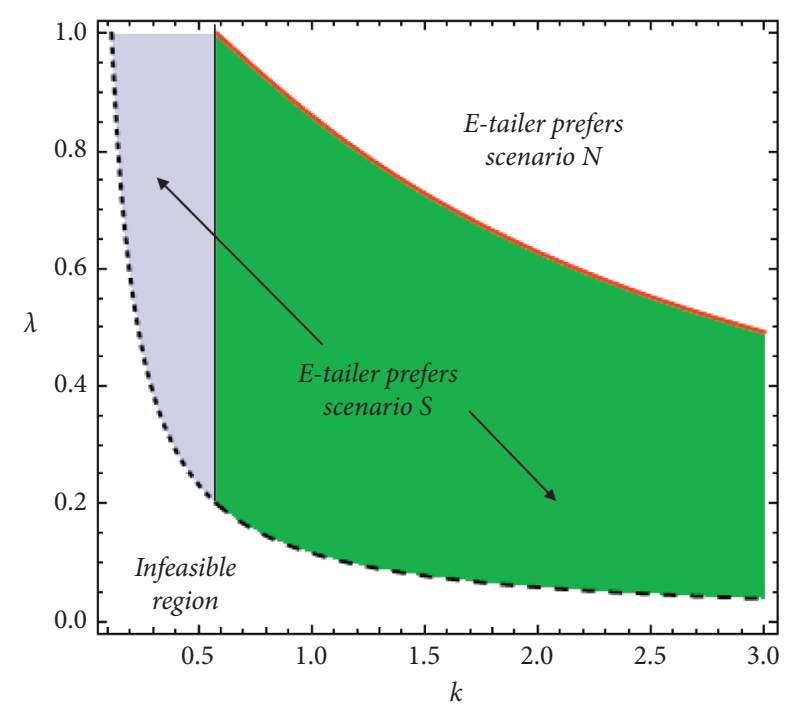

(b)

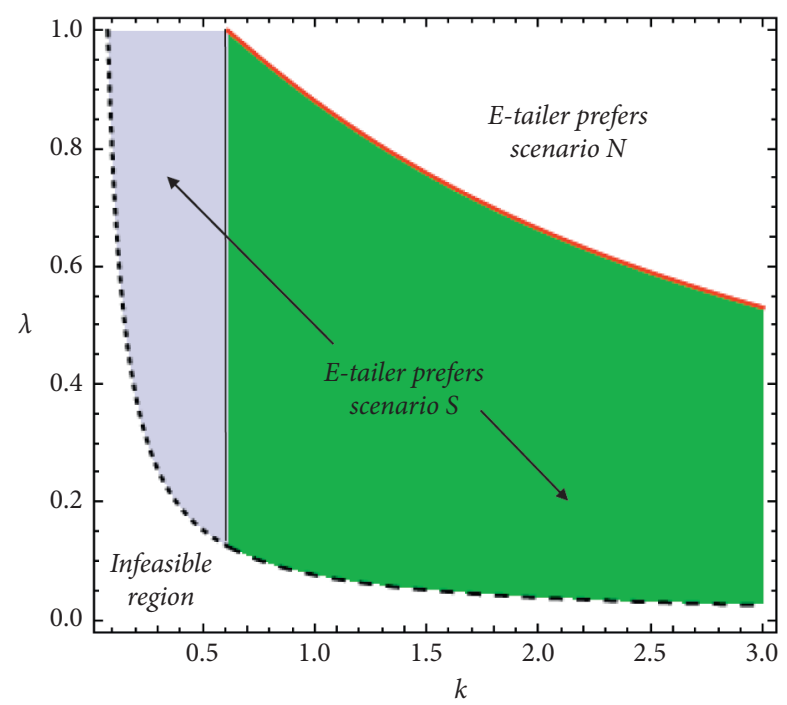

(d)

FIGURE 4: Impact of product substitutability on the e-tailer's preferences. (a) $\gamma=0.5, \sigma=0.5$. (b) $\gamma=1.5, \sigma=0.5$. (c) $\gamma=3, \sigma=0.5$. (d) $\gamma=6, \sigma=0.5$.

\section{Conclusion}

We formulate two scenarios to study the e-tailer' preferences over market information sharing, namely, (1) Scenario $N$, where the two suppliers cannot access the market information and suffer a low product development efficiency, and (2) Scenario $S$, where the e-tailer shares market information with the two suppliers, and thus both of them enjoy a higher product development efficiency.

We show that, given a high product development efficiency or a low production development efficiency with a high efficiency improvement rate, the e-tailer prefers sharing market information with its two suppliers. The reasons are as follows. We note that the e-tailer's profits can be divided into two parts, that is, (1) the riskless profit and (2) the risk profit because of market information sharing. We find that the e-tailer always obtains a higher riskless profit in Scenario S because it can increase retail margin in Scenario S significantly, which covers its market demand size loss in Scenario S. However, whether the e-tailer can obtain higher risk profit in Scenario S depends on the two suppliers' production development efficiency and the efficiency improvement rate because of market information sharing. Given a high product development efficiency, the e-tailer enjoys higher riskless and risk profits, so it prefers sharing information. Given a low product development efficiency with a high efficiency improvement rate, the e-tailer suffers risk profit loss but its riskless profit advantage in Scenario $S$ is more significant, which dominates the risk profit loss. Hence, market information sharing is preferred for the e-tailer in this case. We then study whether the two suppliers can be better off because of market information sharing. We find 
that the two suppliers obtain higher profits in Scenario S because their wholesale prices increment is so significant that it offsets the loss of market sizes.

Conducting numerical analysis, we find that the option of market information sharing will be less and less (more and more) attractive for the e-tailer as market uncertainty (product substitutability) increases. That is to say, market uncertainty (product substitutability) acts as a negative (positive) driving force that hinders (encourages) the e-tailer from preferring (to choose) market information sharing. These observations may be insightful for e-tailers that are planning to launch the projects such as market information/ data sharing.

Our findings can be insightful for the e-tailers and the suppliers. For example, when suppliers are efficient in product development (e.g., Huggies, a well-known diaper brand), the e-tailers with strong information technology like JD, whose market information is considered to be insightful for product development, are suggested to choose to share market information with their suppliers. On the contrary, when the suppliers are not efficient in product development (i.e., some startup brands), e-tailers are suggested to select a market information sharing strategy when the suppliers are worthy of helping (i.e., the efficiency improvement rate is high). For the suppliers, we reveal that the market information is very helpful for their performance improvement, so both of them should seek the support of market information.

\section{Appendix}

Note that all of the proofs of lemmas and propositions are conducted in the feasible region of $k$ and $\lambda$ on $\Omega=\left\{(k, \lambda) \mid k>k_{0}=\left(2(1+\gamma)^{2} /(2+\gamma)^{2}(2+3 \gamma)\right),(2(1+\right.$ $\left.\left.\gamma)^{2} /(2+\gamma)^{2}(2+3 \gamma) k\right)=\lambda_{0}<\lambda<1\right\}$.

\section{Proof. of Lemma 3:}

The difference between $E\left[d_{S 1}^{S}\right]$ and $E\left[d_{S 1}^{N}\right]$ is

$$
E\left[d_{S 1}^{S}\right]-E\left[d_{S 1}^{N}\right]=\frac{2 k(1+\gamma)^{2}(2+\gamma)^{2}(2+3 \gamma)(1-\lambda)}{\left[k(2+\gamma)^{2}(2+3 \gamma)-2(1+\gamma)^{2}\right]\left[\lambda k(2+\gamma)^{2}(2+3 \gamma)-2(1+\gamma)^{2}\right]}
$$

Note that $k(2+\gamma)^{2}(2+3 \gamma)-2(1+\gamma)^{2}$ increases in $k$ and it has the minimum value at $k=k_{0}=2(1+\gamma)^{2} /(2+$ $\gamma)^{2}(2+3 \gamma)$. Substituting $k_{0}$ into $k(2+\gamma)^{2}(2+3 \gamma)-$ $(2+\gamma)^{2}$, we get $k(2+\gamma)^{2}(2+3 \gamma)-\left.2(1+\gamma)^{2}\right|_{k=k_{0}}=0$. Therefore, we have $k(2+\gamma)^{2}(2+3 \gamma)-2(1+\gamma)^{2}>0$ because $k>k_{0}$ in our feasible region. Furthermore, it is easy to verify that $\lambda k(2+\gamma)^{2}(2+3 \gamma)-2(1+\gamma)^{2}>0$. and $\lambda$.

Therefore, we have $E\left[d_{S 1}^{S}\right]>E\left[d_{S 1}^{N}\right]$ for any feasible $\gamma, k$,

Similarly, $E\left[d_{S 2}^{S}\right]>E\left[d_{S 2}^{N}\right]$ can be proven.

Hence, Lemma 3 is proven.

Proof. of Lemma 4:

The difference between $E\left[w_{S 1}^{S}\right]$ and $E\left[w_{S 1}^{N}\right]$ is

$$
E\left[w_{S 1}^{S}\right]-E\left[w_{S 1}^{N}\right]=\frac{2 k(1+\gamma)^{2}(2+\gamma)^{2}(2+3 \gamma)(1-\lambda)}{\left[k(2+\gamma)^{2}(2+3 \gamma)-2(1+\gamma)^{2}\right]\left[\lambda k(2+\gamma)^{2}(2+3 \gamma)-2(1+\gamma)^{2}\right]}
$$

Note that $k(2+\gamma)^{2}(2+3 \gamma)-2(1-\lambda)^{2}$ increases in $k$ and it has the minimum value at $k=k_{0}=2(1+\gamma)^{2} /(2+$ $\gamma)^{2}(2+3 \gamma)$. Substituting $k_{0}$ into $k(2+\gamma)^{2}(2+3 \gamma)-$ $2(1+\gamma)^{2}$, we get $k(2+\gamma)^{2}(2+3 \gamma)-\left.2(1+\gamma)^{2}\right|_{k=k_{0}}=0$. Therefore, we have $k(2+\gamma)^{2}(2+3 \gamma)-2(1+\gamma)^{2}>0$ because $k>k_{0}$ in our feasible region. Furthermore, it is easy to verify that $\lambda k(2+\gamma)^{2}(2+3 \gamma)-2(1+\gamma)^{2}>0$.
Therefore, we have $E\left[w_{S 1}^{S}\right]>E\left[w_{S 1}^{N}\right]$ for any feasible $\gamma, k$, and $\lambda$.

Similarly, $E\left[w_{S 2}^{S}\right]>E\left[w_{S 2}^{N}\right]$ can be proven.

Hence, Lemma 4 is proven.

Proof. of Lemma 5:

The difference between $E\left[m_{S 1}^{S}\right]$ and $E\left[m_{S 1}^{N}\right]$ is

$$
E\left[m_{S 1}^{S}\right]-E\left[m_{S 1}^{N}\right]=\frac{k(1+\gamma)^{2}(2+\gamma)^{2}(2+3 \gamma)(1-\lambda)}{\left[k(2+\gamma)^{2}(2+3 \gamma)-2(1+\gamma)^{2}\right]\left[\lambda k(2+\gamma)^{2}(2+3 \gamma)-2(1+\gamma)^{2}\right]}
$$

Note that we have proven $k(2+\gamma)^{2}(2+3 \gamma)-$ $2(1+\gamma)^{2}>0$ and $\lambda k(2+\gamma)^{2}(2+3 \gamma)-2(1+\gamma)^{2}>0$. Therefore, we have $E\left[m_{S 1}^{S}\right]>E\left[m_{S 1}^{N}\right]$ for any feasible $\gamma, k$, and $\lambda$. 
Similarly, $E\left[m_{S 2}^{S}\right]>E\left[m_{S 2}^{N}\right]$ can be proven.

Hence, Lemma 5 is proven.
Proof. of Lemma 6:

The difference between $E\left[q_{S 1}^{S}\right]$ and $E\left[q_{S 1}^{N}\right]$ is

$$
E\left[q_{S 1}^{S}\right]-E\left[q_{S 1}^{N}\right]=\frac{k(1+\gamma)^{2}(2+\gamma)^{2}(2+3 \gamma)(1-\lambda)}{\left[k(2+\gamma)^{2}(2+3 \gamma)-2(1+\gamma)^{2}\right]\left[\lambda k(2+\gamma)^{2}(2+3 \gamma)-2(1+\gamma)^{2}\right]}
$$

Note that we have proven $k(2+\gamma)^{2}(2+3 \gamma)-2$ $(1+\gamma)^{2}>0$ and $\lambda k(2+\gamma)^{2}(2+3 \gamma)-2(1+\gamma)^{2}>0 \sqrt{b^{2}-4 a c}$. Therefore, we have $E\left[q_{S 1}^{S}\right]>E\left[q_{S 1}^{N}\right]$ for any feasible $\gamma, k$, and $\lambda$.

Similarly, $E\left[q_{S 2}^{S}\right]>E\left[q_{S 2}^{N}\right]$ can be proven.
Hence, Lemma 6 is proven.

Proof. of Proposition 1

The difference of $\pi_{R}^{S}$ and $\pi_{R}^{N}$ is

$$
\pi_{R}^{S}-\pi_{R}^{N}=\frac{A \lambda^{2}+B \lambda+C}{2\left(-2+8 k-4 \gamma+20 k \gamma-2 \gamma^{2}+14 k \gamma^{2}+3 k \gamma^{3}\right)^{2}\left(-2-4 \gamma-2 \gamma^{2}+8 k \lambda+20 k \gamma \lambda+14 k \gamma^{2} \lambda+3 k \gamma^{3} \lambda\right)^{2}}
$$

where $\quad A=-k^{2}(2+\gamma)^{2}(2+3 \gamma)^{2}\left\{4(1+\gamma)^{4}\left[(1+\gamma)^{2}+\right.\right.$ $\left.\left.f_{1}(k, \gamma)\right]+(3+2 \gamma)\left[f_{1}(k, \gamma)\right]^{2} \sigma^{2}\right\}, B=4 k(1+\gamma)^{2}(2+\gamma)^{2}$ $(2+3 \gamma)\left\{f_{2}(k, \gamma)+\left[f_{1}(k, \gamma)\right]^{2} \sigma^{2}\right\}$, and $C=-4 k^{2}(1+\gamma)^{6}$ $(2+\gamma)^{2}(2+3 \gamma)^{2}-4(1+\gamma)^{4}\left[f_{1}(k, \gamma)\right]^{2} \sigma^{2}$.
We find that the sign of $\pi_{R}^{S}-\pi_{R}^{N}$ depends on $A \lambda^{2}+B \lambda+{ }_{C}$, which is a quadratic function with respect to $\lambda$. Solving $A \lambda^{2}+B \lambda+C=0$, we have two roots $\lambda_{1}$ and $\lambda_{3}$ $\left(\lambda_{3}<\lambda_{1}\right)$ as follows:

$$
\begin{aligned}
& \lambda_{1}=2 \frac{(1+\gamma)^{2}\left\{(2+\gamma)\left[f_{2}(k, \gamma)+\left(\sigma f_{1}(k, \gamma)\right)^{2}\right]+(1+\gamma) f_{1}(k, \gamma) \sqrt{\left(1+\sigma^{2}\right)\left[f_{2}(k, \gamma)+\left(\sigma f_{1}(k, \gamma)\right)^{2}\right]}\right\}}{k(2+3 \gamma)(2+\gamma)\left\{4(1+\gamma)^{4}\left[(1+\gamma)^{2}+f_{1}(k, \gamma)\right]+(3+2 \gamma)\left(\sigma f_{1}(k, \gamma)\right)^{2}\right\}}, \\
& \lambda_{3}=2 \frac{(1+\gamma)^{2}\left\{(2+\gamma)\left[f_{2}(k, \gamma)+\left(\sigma f_{1}(k, \gamma)\right)^{2}\right]-(1+\gamma) f_{1}(k, \gamma) \sqrt{\left(1+\sigma^{2}\right)\left[f_{2}(k, \gamma)+\left(\sigma f_{1}(k, \gamma)\right)^{2}\right]}\right\}}{k(2+3 \gamma)(2+\gamma)\left\{4(1+\gamma)^{4}\left[(1+\gamma)^{2}+f_{1}(k, \gamma)\right]+(3+2 \gamma)\left(\sigma f_{1}(k, \gamma)\right)^{2}\right\}} .
\end{aligned}
$$

According to Vieta's theorem, we have

$$
\begin{gathered}
\lambda_{1}+\lambda_{3}=-\frac{B}{A}=\frac{4(1+\gamma)^{2}\left(k^{2}(1+\gamma)^{2}(2+\gamma)^{2}(2+3 \gamma)^{2}+\left(-2(1+\gamma)^{2}+k(2+\gamma)^{2}(2+3 \gamma)^{2}\right)^{2} \sigma^{2}\right)}{k(2+3 \gamma)\left(4(1+\gamma)^{4}\left(-(1+\gamma)^{2}+k(2+\gamma)^{2}(2+3 \gamma)^{2}\right)+(2+3 \gamma)\left(-2(1+\gamma)^{2}+k(2+\gamma)^{2}(2+3 \gamma)^{2}\right)^{2} \sigma^{2}\right)}>0 \\
\lambda_{1} \lambda_{3}=\frac{C}{A}=\frac{-4 k^{2}(1+\gamma)^{6}(2+\gamma)^{2}(2+3 \gamma)^{2}-4(1+\gamma)^{4}\left(-2(1+\gamma)^{2}+k(2+\gamma)^{2}(2+3 \gamma)^{2}\right)^{2} \sigma^{2}}{k(2+3 \gamma)\left(4(1+\gamma)^{4}\left(-(1+\gamma)^{2}+k(2+\gamma)^{2}(2+3 \gamma)^{2}\right)+(3+2 \gamma)\left(-2(1+\gamma)^{2}+k(2+\gamma)^{2}(2+3 \gamma)^{2}\right)^{2} \sigma^{2}\right)}<0 .
\end{gathered}
$$

This indicates that $\lambda_{3}<0<\lambda_{1}$. Hence, we only need to examine the feasibility of $\lambda_{1}$. We first compare $\lambda_{1}$ and 1 and have the following conditions: 
(a) If $\lambda_{1}>1$, which can be simplified to $k<2(1+\gamma)^{2}$ / $(2+3 \gamma)(2+\gamma)$

(b) If $\lambda_{1}>1$, which can be simplified to $k>2(1+\gamma)^{2}$ / $(2+3 \gamma)(2+\gamma)$
We first compare $\lambda_{1}$ and $\lambda_{0}=2(1+\gamma)^{2} /(2+3 \gamma)(2+$ $\gamma) k$ and have

$$
\begin{aligned}
\lambda_{1} & =2 \frac{(1+\gamma)^{2}\left\{(2+\gamma)\left[f_{2}(k, \gamma)+\left(\sigma f_{1}(k, \gamma)\right)^{2}\right]+(1+\gamma) f_{1}(k, \gamma) \sqrt{\left(1+\sigma^{2}\right)\left[f_{2}(k, \gamma)+\left(\sigma f_{1}(k, \gamma)\right)^{2}\right]}\right\}}{k(2+3 \gamma)(2+\gamma)\left\{4(1+\gamma)^{4}\left[(1+\gamma)^{2}+f_{1}(k, \gamma)\right]+(3+2 \gamma)\left(\sigma f_{1}(k, \gamma)\right)^{2}\right\}}>\lambda_{0} \\
& =\frac{2(1+\gamma)^{2}}{(2+\gamma)^{2}(2+3 \gamma) k}
\end{aligned}
$$

Therefore, we have $A \lambda^{2}+B \lambda+C>0$ and $\pi_{R}^{S}-\pi_{R}^{N}>0$ if one of the conditions holds:

(c) $k_{0}<k \leq k_{1}=2(1+\gamma)^{2} /(2+3 \gamma)(2+\gamma)$

(d) $k>k_{1}$ and $\lambda_{0}<\lambda<\lambda_{1}$

Hence, Proposition 1 is proven.

Proof. of Corollary 1: The proof of Corollary 1 is similar to the proof of Proposition 1; we, therefore, omit it here.

Proof. of Proposition 2: The proof of Proposition 2 is similar to the proof of Proposition 1; we, therefore, omit it here.

\section{Data Availability}

No data were used to support this study.

\section{Conflicts of Interest}

The authors declare that they have no conflicts of interest.

\section{Acknowledgments}

This work was supported by Guangdong Basic and Applied Basic Research Foundation (no. 2019A1515011526) and National Natural Science Foundation of China (no. 71672061). The corresponding author is Zhaoquan Jian.

\section{References}

[1] Mckinsey \& Company, eBook: Big Data, Analytics, and the Future of Marketing \& Sales, Mckinsey \& Company, New York, NY, USA, 2013, https://www.mckinsey.com/businessfunctions/marketing-and-sales/our-insights/ebook-big-dataanalytics-and-the-future-of-marketing--sales\#.

[2] T. Davenport, "Analytics 3.0," Harvard Business Review, vol. 91, pp. 64-72, 2013.

[3] M. Salehan and D. J. Kim, "Predicting the performance of online consumer reviews: a sentiment mining approach to big data analytics," Decision Support Systems, vol. 81, pp. 30-40, 2016.

[4] Statista, Big Data Initiatives and Success Rate Among Corporations in the United States and Worldwide, Statista, Hamburg, Germany, 2018, https://www.statista.com/ statistics/742935/worldwide-survey-corporate-big-datainitiatives-and-success-rate/.

[5] S. Huang, X. Guan, and Y.-J. Chen, "Retailer information sharing with supplier encroachment," Production and Operations Management, vol. 27, no. 6, pp. 1133-1147, 2018.

[6] A. Y. Ha, S. Tong, and H. Zhang, "Sharing demand information in competing supply chains with production diseconomies," Management Science, vol. 57, no. 3, pp. 566-581, 2011.

[7] L. Li, "Information sharing in a supply chain with horizontal competition," Management Science, vol. 48, no. 9, pp. 1196-1212, 2002.

[8] JD.com, JD's Data Insights Help Top Consumer Goods Brands Boost Sales, JD. Com, Beijing, China, 2019, https:// jdcorporateblog.com/jds-data-insights-help-top-consumergoods-brands-boost-sales/.

[9] Amazon, AWS Marketplace Enhanced Data Sharing Program, Amazon, Seattle, Was, USA, 2015, https://docs.aws. amazon.com/marketplace/latest/userguide/enhanced-data -sharing-program.html.

[10] S. Kraiselburd, V. Narayanan, and A. Raman, "Contracting in a supply chain with stochastic demand and substitute products," Production and Operations Management, vol. 13, no. 1, pp. 46-62, 2004.

[11] K. Zhu, R. Q. Zhang, and F. Tsung, "Pushing quality improvement along supply chains," Management Science, vol. 53, no. 3, pp. 421-436, 2007.

[12] V. Krishnan and K. T. Ulrich, "Product development decisions: a review of the literature," Management Science, vol. 47, no. 1, pp. 1-21, 2001.

[13] S. R. Bhaskaran and V. Krishnan, "Effort, revenue, and cost sharing mechanisms for collaborative new product development," Management Science, vol. 55, no. 7, pp. 1152-1169, 2009.

[14] J. Wang and H. Shin, "The impact of contracts and competition on upstream innovation in a supply chain," Production and Operations Management, vol. 24, no. 1, pp. 134-146, 2015.

[15] D.-H. Yoon, "Supplier encroachment and investment spillovers," Production and Operations Management, vol. 25, no. 11, pp. 1839-1854, 2016.

[16] B. Hu, Y. Mai, and S. Pekeč, "Managing innovation spillover in outsourcing," Production and Operations Management, vol. 29, no. 10, pp. 2252-2267, 2020.

[17] E. Gal-Or, "Information sharing in oligopoly," Econometrica, vol. 53, no. 2, pp. 329-343, 1985.

[18] E. Gal-Or, "Information transmission--cournot and Bertrand equilibria," The Review of Economic Studies, vol. 53, no. 1, pp. 85-92, 1986. 
[19] L. Li, "Cournot oligopoly with information sharing," The RAND Journal of Economics, vol. 16, no. 4, pp. 521-536, 1985.

[20] X. Vives, "Duopoly information equilibrium: cournot and Bertrand," Journal of Economic Theory, vol. 34, no. 1, pp. 71-94, 1984.

[21] W. H. J. Chu and C. C. Lee, "Strategic information sharing in a supply chain," European Journal of Operational Research, vol. 174, no. 3, pp. 1567-1579, 2006.

[22] L. Li and H. Zhang, "Confidentiality and information sharing in supply chain coordination," Management Science, vol. 54, no. 8, pp. 1467-1481, 2008.

[23] W. Bian, J. Shang, and J. Zhang, "Two-way information sharing under supply chain competition," International Journal of Production Economics, vol. 178, pp. 82-94, 2016.

[24] T.-M. Choi, K. Govindan, X. Li, and Y. Li, "Innovative supply chain optimization models with multiple uncertainty factors," Annals of Operations Research, vol. 257, no. 1-2, pp. 1-14, 2017.

[25] H. Lei, J. Wang, H. Yang, and H. Wan, "The impact of ex-post information sharing on a two-echelon supply chain with horizontal competition and capacity constraint," Forthcoming at Annals of Operations Research, 2020.

[26] T. W. McGuire and R. Staelin, "An industry equilibrium analysis of downstream vertical integration," Marketing Science, vol. 2, no. 2, pp. 161-191, 1983.

[27] R. Ganeshan, J. E. Tyworth, and Y. Guo, "Dual sourced supply chains: the discount supplier option," Transportation Research Part E: Logistics and Transportation Review, vol. 35, no. 1, pp. 11-23, 1999.

[28] A. Arya, B. Mittendorf, and D. E. M. Sappington, "The bright side of supplier encroachment," Marketing Science, vol. 26, no. 5, pp. 651-659, 2007.

[29] Z. Hong and X. Guo, "Green product supply chain contracts considering environmental responsibilities," Omega, vol. 83, pp. 155-166, 2019.

[30] X. Guan, B. Liu, Y. Chen, and H. Wang, "Inducing supply chain transparency through supplier encroachment," Production and Operations Management, vol. 29, no. 3, pp. 1059-1478, 2020.

[31] A. Tsay, "Designing and controlling the outsourced supply chain," Foundations \& Trends in Technology Information \& Operations Management, vol. 7, no. 1-2, pp. 1-160, 2014.

[32] P. Crama, B. De Reyck, and N. Taneri, "Licensing contracts: control rights, options, and timing," Management Science, vol. 63, no. 4, pp. 1131-1149, 2017.

[33] Z. Ge, Q. Hu, and Y. Xia, "Firms' R\&D cooperation behavior in a supply chain," Production and Operations Management, vol. 23, no. 4, pp. 599-609, 2014.

[34] W. Shang, A. Ha, and S. Tong, "Information sharing in a supply chain with a common retailer," $\backslash$ Management Science, vol. 62 , no. 1, pp. 245-263, 2016.

[35] R. Shi, J. Zhang, and J. Ru, "Impacts of power structure on supply chains with uncertain demand," Production and Operations Management, vol. 22, no. 5, pp. 1232-1249, 2013.

[36] E. S. Mills, "Uncertainty and price theory," Quarterly Journal of Economics, vol. 73, no. 1, pp. 116-130, 1959.

[37] N. C. Petruzzi and M. Dada, "Pricing and the newsvendor problem: a review with extensions," Operations Research, vol. 47, no. 2, pp. 183-194, 1999. 